Please do not remove this page

RMIT

UNIVERSITY

\title{
Postformal priorities for postnormal times: A rejoinder to Ziauddin Sardar
}

Gidley, Jennifer

https://researchrepository.rmit.edu.au/esploro/outputs/9921857811801341/filesAndLinks?institution=61RMIT_INST\&index=null

Gidley, J. (2010). Postformal priorities for postnormal times: A rejoinder to Ziauddin Sardar. Futures: The Journal of Policy, Planning and Futures Studies, 42(6), 625-632.

https://doi.org/10.1016/j.futures.2010.04.022

Document Version: Accepted Manuscript

Published Version: https://doi.org/10.1016/j.futures.2010.04.022

Repository homepage: https://researchrepository.rmit.edu.au

(C)2010 Elsevier Ltd. All rights reserved

Downloaded On 2023/04/26 16:15:33 +1000

Please do not remove this page 
Gidley, J 2010, 'Postformal priorities for postnormal times - A rejoinder to Ziauddin Sardar', Futures: The Journal of Policy, Planning and Futures Studies, vol. 42, no. 6, pp. 625-632.

\title{
Postformal Priorities for Postnormal Times-A Playful Paradox (A Rejoinder to Ziauddin Sardar)
}

\section{Jennifer M. Gidley}

Global Cities Research Institute

School of Global Studies, Social Science and Planning, RMIT University, GPO Box 2476V, Melbourne 3001, Australia *j.gidley@planetaryfutures.com.au

\begin{abstract}
This essay is a postformal rejoinder to Ziauddin Sardar's Welcome to Postnormal Times. I have no quarrel with Sardar's conclusion that these times are postnormal, nor do I disagree with many of his observations, but our standpoints regarding implications are somewhat contradictory. Paradoxically, rather than jump into an old paradigm form of debate with Sardar's interpretations of postnormalcy, this rejoinder is a playful postformal response. I celebrate our complementary views as expressions of the complex truths of multiperspectivality. First I question the meaning of normal and postnormal in the context of such notions as "the pathology of normalcy." Secondly I begin to explore the postnormal circumstances from a postformal perspective. This involves discussion of notions of progress, development, evolution and co-evolution from different points of view as an opener to coming to terms with complexity. I then explore how concepts such as complexity and paradox can be understood as paths to wisdom; how active imagination can be engaged in the service of life; and how engaged imagination can unfold new normative narratives of alternative futures. Such imaginaries of hope are vital for the wellbeing of young people. The essay closes with a call to embrace the richness of complexity and play with - rather than fear-the paradox of planetary pluralism.
\end{abstract}

We will have to imagine ourselves out of postnormal times and into a new age of normalcy - with an ethical compass and a broad spectrum of imaginations from the rich diversity of human cultures. [1]

In this essay I take the opportunity to respond to Ziauddin Sardar's essay Welcome to Postnormal Times with a postformal rejoinder. Einstein gave us the clue over one hundred years ago with his statement that "The significant problems we have cannot be solved at the same level of thinking with which we created them." A key feature of the level of thinking that has led the dominant worldview for the last few centuries - and thus contributed to the many challenges of our times - was identified and described early this century by Jean Piaget, developmental psychologist/philosopher. He called it "formal operations" [2]. One of its fundamental premises is propositional logic - that "every statement is either true or false and not both" [3]. If our dominant mode of thinking is formal operations, based on binary logic, we may have a lot of trouble dealing with the tensions created by a multiperspectival world - we may feel overwhelmed by chaos, complexity and contradiction. So what was Einstein hinting at? Did he have insight into higher stages of reasoning? Arguably the answer is yes. Perhaps best known for his theory of relativity, Einstein was a redoubtable postformal thinker who engaged not just formal logic, but a range of postformal logics such as creativity, complexity, paradox, imagination, inspiration, intuition and many other ways of knowing that find their way into the psychology literature on postformal reasoning. 
I suggest in this essay and other papers that in order to deal with postnormal times we need to encourage and enact postformal reasoning $[4,5]$ and furthermore we need to consciously develop and promote postformal pedagogies to educate future generations to better deal with the increasing uncertainties of postnormal futures [6-8].

I wonder at the rich diversity of appearances, values, worldviews and outlooks we can observe within the "one human nature" of our human species. I wonder even more how we can reduce the rich textures of this diversity down to simple binaries like "us" and "them." Perhaps most of us have difficulty comprehending complex diversity and thus we feel compelled to reduce it, for convenience, to simple binaries. Undoubtedly simple binaries make some kind of sense in practical, physical, spatial settings: for example, up and down, left and right, forward and back. However, binaries have less explanatory power the more we move from simple mechanisms that can be explained by classical physics to more complex botanical, zoological and ultimately human life and other noospheric forms. If we really bring our full awareness to bear on the complexity of human nature - with its physical, vital, emotional, mental, socio-cultural and moral/ethical dimensions - it soon becomes clear that using simple binary logic as our highest form of reasoning is far from optimum.

In order to better understand the default tendency of the dominant worldview to cling to binary categorizations to simplify knowledge, it is helpful to understand the bigger picture context of how, and when, we humans came to think like this in the first place. Taking a macrohistorical perspective of our collective cultural evolution as a species

(nothwithstanding diverse ethnocultural differences and complex non-linear genealogies) the beginnings of formal binary logic can be located in Athenian Greece with Aristotelian philosophy [4]. This underlying binary characteristic of Western philosophy is in contrast to the dialectical lineage of Chinese philosophy, more pluralistic Hindic cosmologies, or more unitive indigenous worldviews. Western dualism was further sharpened in the $17^{\text {th }}$ century by the Cartesian dualism - mind/body split — that has since pervaded modern scientific positivism and analytic philosophy.

From a socio-cultural and geo-political perspective binary logic also served the development of Nation-states. Such questions as "Who is a National?" and "Who is a foreigner?" are based on formal logic and have supported the cultural evolutionary formation of Nation-states. But Nation-states, like agricultural settlements and tribes before them are mere phases in a much bigger-picture human cultural evolution and we — as a species — are arguably right in the middle of a major transition to a planetary imaginary. ${ }^{1}$ Integral philosopher, Jean Gebser $(1949 / 1985)$ proposed that instead of being fixed conceptions, nations could be "dynamic efflorescences of a larger cultural context" [10] (p. 291). What type of thinking might we need to cultivate if we are to build a non-hegemonic, richly pluralistic and sustainable planetary culture that celebrates such "dynamic efflorescences" rather than homogenising diversity?

From the perspective of individual psychological development, classical Piagetian developmental psychology theorises that the ability to distinguish binary categories is a necessary part of formal operations, and even part of the process of identify-formation in adolescence. An appropriate phase of adolescent development is to distinguish between "us" (peers) and "them" (parents). But as research undertaken by adult developmental

\footnotetext{
${ }^{1}$ This movement has been conceptualised by political scientist, Manfred Steger, as "the rise of the global imaginary" [9].
} 
psychologists - particularly in the USA - over the last few decades has indicated other, higher order ways of reasoning are being identified which are more appropriate to adult levels of maturity, and more suited to dealing with the complexity of $21^{\text {st }}$ century challenges.

In the complex, globalizing, mobilizing world of today, it no longer makes sense to categorise our fellow humans in such simple binary terms as "white or coloured", "local or foreign", "Western or Eastern" or even "male or female." The intermingling and interconnectedness of all types of identities and subjectivities - as well as the underlying power relations among them - have been exposed in the second half of the $20^{\text {th }}$ century by theorists from critical, feminist, postcolonial, postmodern and poststructural persuasions, to name a few. This gradual but relentless exposé of the underbelly of modernist ideologieswith their right/wrong, black/white, developed/undeveloped categorical containers - has intensified in the chaos and complexity of the last few decades that Sardar explores so eloquently in his essay Welcome to Postnormal Times. From a futures perspective it seems likely that this "chaos, complexity and contradiction" will continue to increase and further unsettle our "tidy-town $19^{\text {th }}$ century knowledge categories and cartographies" as we struggle as a species to weather the uncertainties of the $21^{\text {st }}$ century and beyond.

The dangerous limitations of applying binary logic to complex human situations is highlighted in the now famous response of former US President Bush to the violence and destruction of the Twin Towers' implosion: "you're either with us or you're with the enemy." Many people in the so-called "free world" that the USA claims to lead, did not agree with the fundamentalism in Bush's simplistic binaries of "us and them" and "good vs evil" any more than they agreed with this same binary when applied by "fundamentalist others." Nor do many agree that the Twin Towers attack, no matter how violent, justified an Iraq war.

Some of the worst cultural atrocities of the last three centuries have resulted from the Faustian combination of hegemonic political power with the binary logic of dualistic thinking - "if I am right and we disagree, then you must be wrong." This archetypal "us" versus "them" hegemony was most obviously enacted via violent colonial invasions of indigenous lands, e.g. by the Spanish and later British Empires. French philosopher Edgar Morin refers to the early period of colonisation - beginning in the late $15^{\text {th }}$ century - as the beginning of the Planetary era [11]. The multi-dimensional devastation wrought by the Spanish colonisation of the Americas could be regarded as a proto-type of globalization - a harsh globalization based on domination and cultural homogeneity. On the other hand Teilhard de Chardin's notion of planetization, which infuses Morin's notion of the kind of planetary era we need to co-create, is of a different ethos as indicated in the conclusion.

The harsh form of globalization can be more recently observed in the neo-imperialism of late $20^{\text {th }}$ century US foreign policy. From this potent mix of dualism combined with hegemony arise self-righteous colonising — and/or invading - powers weighted against oppressed and marginalised cultures, whose very ways of knowing and defending themselves are regarded as completely valueless by the dominant power [12]. In the vast body of material that has been written about conflict and war, it seems to me that there is an underappreciation of the central role of dualistic thinking, based on binary logic, in creating and maintaining conflict. There is even less appreciation of the potential role of key features of postformal reasoning in moving humanity out of the conflict-arousing binary deadlock towards postformal logics such as dialogue, creativity, reflexivity and paradoxical reasoning. 


\section{Beyond "Normalcy"—Breakdown or Breakthrough?}

"Never doubt that a small group of thoughtful, committed citizens can change the world." (Margaret Mead) ${ }^{2}$

So yes, Sardar is right. We are living in "postnormal times." He presents this postnormal condition as mostly bad news. I would like to challenge this assumption from a number of angles - an inherently postformal manoevre. If by "normal" we are referring to the dominant worldview of modernity - with its neoliberal economic policies of "profit before planet" and its secular values associated with scientific materialism - then perhaps the sense that these sacred cows are unravelling is not as bad as it may first appear. Since at least the 1950s critical social theorists have begun to seriously question the complex relationships among normalcy, sanity, health, insanity and so called civilized society. They brought into question the health and sanity of what we refer to as "normalcy" turning concepts of sanity and madness on their heads. This critique has come from many directions: the humanistic socialpsychological reflections of Erich Fromm on the "pathology of normalcy" [13]; the radical psychiatry perspectives of R.D.Laing [14] and Thomas Szasz [15]; and the critical cultural analyses of Herbert Marcuse [16] and Michel Foucault [17] to name a few.

But there is another side to the accelerated change that comes with postnormality. Accelerated change can facilitate, perhaps even precipitate, the kind of tipping point during which major transformations can occur [18]. If a sufficient critical mass of participants are committed to using the leverage of a chaos tipping point to align efforts to create normative, ethical, pluralistic, collaborative, socially just and ecologically sound futures, much could be done to transform the global-societal challenges of these postnormal times. In contrast with the fear and hopelessness that can be generated by trying to control and/or escape from the increasing chaos, complexity and contradiction in our external world, there are many signs afoot of positive, creative developments stirring in our inner worlds and being mobilised through global collaborative networks [19]. The signs of hopeful change and positive inner developments in human culture and consciousness will be the primary focus of the remainder of this essay.

\section{Postnormal Times from a Postformal Perspective}

To have any notion of a viable future, we must grasp the significance of this period of transition which is characterised by three c's: complexity, chaos and contradictions. [1]

Ironically, several of the key notions that Sardar refers to as being the rather disturbing markers of postnormality, such as complexity, chaos and contradictions, leading to uncertainty, are closely related to key features that adult developmental psychologists identify as representing signs of postformal reasoning. Postformal is the most widely used psychological term to denote higher developmental stages beyond Piaget's formal operations - other terms include "post-conventional" [20], "hierarchical complexity" [21] and "vision-logic" [22]. Adult developmental psychologists have been researching postformal thinking for several decades, identifying up to four stages of postformal development. They identify numerous features of postformal reasoning_-including complexity,

\footnotetext{
${ }^{2}$ Margaret Mead quote used with permission of the Institute for Intercultural Studies. http://www.interculturalstudies.org/faq.html\#quote
} 
contextualisation, creativity, dialectics, dialogue, holism, imagination, construct awareness, paradox, pluralism, reflexivity, spirituality, ${ }^{3}$ values and wisdom [20, 21, 23-36]. Michael Commons has identified a hierarchical complexity of stages of postformal thinking, including systematic, metasystematic, paradigmatic and cross-paradigmatic reasoning [21, 37].

The key features of postformal reasoning that I want to highlight here are complex thinking [35] including paradoxical reasoning [38], creativity and imagination. Complex thinking involves the ability to hold multiple perspectives in mind while at the same time being able to meta-reflect on those perspectives and the potential relationships among them. This is also referred to as metasystemic thinking [39]. Paradoxical thinking is one of the expressions of complex postformal logic. Authors of a recent study that explores the application of postformal reasoning in non-cognitive settings make the following connections between postformal thought, complexity and ability to deal with paradox.

One general aspect of post-formal thought is that one can conceive of multiple logics, choices, or perceptions of an event or relationship, even if seemingly paradoxical, in order to better understand the complexities and inherent biases in "truth." Relationships work on shared "truths" and resolution of logical conflicts. [38].

Postformal logics go beyond Aristotelian formal logic, which requires an either/or response thus creating what is called an "excluded middle." Paradoxical thinking refers to the ability to hold in mind the apparently illogical possibility that two contradictory statements can both be true - or indeed both false. This paradox of the included middle allows for both/and and neither/nor to be correct. Sardar notes in his essay that this "four-fold logic enables us to think in multiples and thus get a better grip on contradictory tensions" [1]. I would also suggest that the attempt to "hold in mind the paradox of contradictory truths - or non-truths" creates uncomfortable tension in the minds and emotions of people only accustomed to using formal logic. This raises the question of how we facilitate the ability of people today to think more complexly and to hold paradox in mind without constantly wanting a resolution of the tension through a reduction of the complexity to a binary. I would argue that it is a global educational priority to lay foundations in childhood and adolescence for the unfoldment of postformal reasoning capacities in adults. We need to develop postformal pedagogies - in which the cultivation of imagination and creativity would be core.

From a postformal perspective, an alternative interpretation of the appearance of chaos, complexity and contradiction in the outer world is that we are being provided with a catalysing challenge for transformation of our inner worlds to keep better pace with what we have done to our external world. As the countenance of the planet shifts dramatically-as it has done before several times - we humans will have to step up to the mark or follow in the footsteps of the dinosaurs. Arguably we have more ability to meet the call not the least because we have been gifted with enough foresight to see it coming. The question remains whether we will act from the foresight in appropriate precautionary ways.

\footnotetext{
${ }^{3}$ The terms spiritual or spirituality, are used in this research, unless otherwise specified, to reflect worldviews that acknowledge that there is more to existence than matter. The use of the term spiritual is thus not intended to denote any particular theological or religious view.
} 


\section{Co-Evolving our Way through Uncertainty}

Postnormal times demands, this paper argues, that we abandon the ideas of 'control and management', and rethink the cherished notions of progress, modernisation and efficiency. [1]

As Sardar indicates, there are a number of problems with modernist notions such as "progress" and "efficiency." Firstly, they are underpinned by industrial era metaphors concerned only with external developments in the world whereby science and technology are put in the service of politico-economic theories of material wealth. Secondly, they build on the contentious 19th century models of social progress and development of Auguste Comte [40] and Herbert Spencer [41]. Such theoretical models were used to rationalize many racist and ethnocentric social abuses - including slavery, colonialism and ethnocide.

These models are both Eurocentric and uni-linear and have been critiqued by many postmodern, postcolonial and integral evolutionary theorists. Cultural anthropologists developed powerful critiques of these models, particularly following on from the early 20th century shift to ethnographic field research. For a few decades the notion of evolution itself came under critique from anthropologists and critical social scientists. However, there has been a revival of interest as new, more integrative anthropological theories began to emerge, such as Marshall Sahlins' theory that there is both evolution of human culture in generalcharacterized by "growing complexity and unilinearity, with culture apparently leaping from one societal form to another," and specific evolution, "to account for the great variety in historical developments" of particular societies [42, p. 214].

Thirdly, the notion of progress is used to justify the rather dubious practice of investing billions of US dollars very year on the search for life on other planets, while the "bottom billion" on this planet struggle to find sufficient resources to have a life at all.

Notwithstanding the above critiques, I happen to have a bias in favour of progressive and developmental notions of individual and socio-cultural evolution and yet I also problematize how these concepts have been used to justify uni-linear Eurocentric evolutionary models [4]. My interest in progress and development is related to inner development — both individual psychological and collective cultural, yet in a pluri-cultural form. My interest in evolution is in conscious co-evolution. While not denying the socio-cultural abuses related to the unilineal, Eurocentric uses of progress and development in late modernity, I seek to recast them in organic-collaborative rather than hegemonic-economic terms. As a whole people on an entire planet we need to progress and develop - not just economically but educationally, emotionally, psychologically, socio-culturally and spiritually. I also wish to reconnect the notions of growth and evolution with their biological-metaphoric roots. In the context of our only planetary home in crisis, it is vital to emphasize life-enhancing metaphors - rather than mechanistic, technicist or digital metaphors. As both a mother and educator, I have witnessed first-hand with children the life-creating processes of growth and development - the unfolding of life and consciousness - in all its uniqueness and universality, its complexity and its poetry. I seek to honour metaphors of inner progress and development and coevolution; of encouraging the current complex-chaotic shift to a postnormal/postformal paradigm with all its contradictions. 


\section{Setting Postformal Priorities-Coming to Terms with Complexity}

Postformal thought can be defined as the ability to think abstractly in recognizing paradoxical issues and dilemmas. This high level of cognition is theoretically above Piaget's last cognitive developmental stage, formal operations. Sinnott [34] suggested that the important aspect of postformal thought is that an individual is able to realize that there can be multiple truths. [38]

Complexity is not only a key feature of postformal reasoning as theorised by adult developmental psychologists but also of post-formal education theory and practice. Joe Kincheloe and Shirley Steinberg pioneered the research on post-formality in education that has inspired much of my own educational futures research [43]. They foreground complexity as a major feature of postmodern times that needs to be addressed by educators.

What Sardar describes as the complexity and chaos of our present times is not news to adult developmental psychologists, postformal educators, complexity scientists/philosophers such as Morin $[44,45]$. Chaos and complexity have not just suddenly emerged on the scene. Arguably chaos has been around since the beginning of time. What is new is that we are beginning as a species to self-reflect on the realisation that life does not fit our neat modernistic categories and that change appears to be accelerating. Some of us also identify the need to theorise what complexity and chaos might mean for all aspects of our lives.

My approach to complexity is informed by what has been termed third generation complexity (as enacted by Nicolescu and Morin) and thus is not restricted to the mathematical and cybernetic approaches of first and second generation complexity science [45-47].

Morin identifies the two major obstacles to addressing the complexity of human life, in the twenty-first century planetary era: biological-anatomical reductionism, and hyperspecialisation [48, p. 34]. Within the modernist academic tradition, based as it has been on scientific empiricism and analytic philosophy, there is a privileging of the metaphysics of materialism, the binary logic of either/or with its excluded middle and the segmentation of knowledge into disciplines - and hyper-specialisations within those. Transdisciplinary theorist, Basarab Nicolescu, approaches these challenges via his approach to transdisciplinarity, incorporating complexity, the included middle and levels of reality [47]. Transdisciplinary transcends the formal epistemological model, whereby knowledge is contained in what have become known as silos, where even sub-fields within disciplines are often not familiar with each other's work. Specialisation brings with it an infinite regress into detail and the separation of knowledge into smaller fragments discussed in narrowing discourses - an academic Tower of Babel. As Morin elaborates: "Fragmented, compartmentalised, mechanized, disjunctive, reductionist intelligence breaks the 'worldcomplex' into disjointed fragments, fractures problems, separates what is connected, makes the multidimensional unidimensional" [48, p. 35]. This creates significant challenges in relation to the complex problems of our times.

By contrast, postformal thinkers who consciously utilise the capacities of active imagination and creativity, complexity and paradoxical reasoning are likely to be better equipped to deal with chaos and contradiction while retaining psychological and cognitive equilibrium.

We may call this capacity wisdom. 


\section{Complexity and Paradox in the Service of Wisdom}

Postformal thought ... is linked to creative production by virtue of its ... multiple views of reality and its multiple solutions, definitions, parameters, and methods during problem solving... [also combining] subjective and objective understanding... the same sorts of processes [can be observed] under the rubrics of wisdom. (Sinnott, 1998, p. 271)

My primary interest in this paper is to reframe Sardar's markers of postnormalitycomplexity, chaos and contradiction-from a positive developmental angle as theorised by positive-adult-developmental psychologists. I don't deny that there is a disturbing aspect to these 'postnormal' occurrences that can be somewhat frightening if we feel that life is beyond our control. Yet they can be recast as significant features of new forms of consciousness breaking through the old binary containers of modernist formal thinking.

Chaos and complexity unsettle all the old categories and thus also the old power relations that held those categories in place. It may help to cope with the associated challenges when we realise that complex thinking, and the ability to hold in mind the contradictions of paradoxical reasoning are indeed important paths to the development of wisdom.

The notion of wisdom - for millennia a central concept in the perennial philosophies (or wisdom traditions) - is a complex, elusive dimension. Adult developmental psychologists suggest that wisdom embraces complexity, multi-perspectivality and creativity $[23,32,34$, $49,50]$. Psychologist Jan Sinnott views wisdom as a complex and integrative characteristic of postformal thought, explicitly linking it with spirituality and creativity [34]. Arthur Koestler foreshadowed the notion of creativity as a postformal feature. He claimed creativity is suppressed by the automatic routines of thought and behaviour that dominate our lives [51].

Recent psychological research reports the disturbing finding that creativity and imagination are declining during childhood - in contrast to most aspects of cognitive developmentperhaps lending support to Koestler's theory [52]. The proposition that this can be attributed to modern education is being further investigated. Psychologists James Kaufman and John Baer characterise creativity as the ability to see things from novel perspectives - reinforcing Sternberg's and Sinnott's links between wisdom, creativity, complexity, and ability to take multiple perspectives [53]. These faculties be nurtured by pedagogical approaches that acknowledge multiple intelligences [54], and/or multiple lines of ability [55]. Further reading on the importance of multiple perspectives and their integration can be found in special issues of this journal on transdisciplinarity [56] and global mindset change [57].

What may be most effective in cultivating wisdom in education is utilising complex thinking, to represent knowledge from multiple perspectives while showing their integral interconnectedness through our creative imagination.

\section{Imagination in the Service of Life}

A thinking that is fragmenting, detached, and rigid will continue to give us a world that is increasingly broken, alien, and dead. The possibility of a living, harmonious, and meaningful world can only be grasped and realised by a thinking and knowing that are themselves living, whole and engaged." [58, p. xiii] 
The significant role of imagination in higher-order thinking, has been under-appreciated academically. Imagination as I use the term is an activity that enables conceptual vitality-it can bring concepts to life. I regard it as a core - if tacit - component in the transitions from formal to postformal thinking. ${ }^{4}$ I suggest that through imagination in our thinking we not only enliven concepts, but we bring the significance of life back into centre focus in our lifeworld, enhancing vitality and wellbeing. Imagination enables the possibility of thinking beyond the already known. From a futures studies perspective this enables us to envision, and thus potentially create, authentically alternative futures. As futures researchers Fred Polak, Elise Boulding, Francis Hutchinson, Ivana Milojevic and others have shown, the power of image is at the centre of creating positive alternative futures [60-63].

The relationship between imagination and post-mechanistic, organic metaphors in philosophical thinking has foundations in the vitality of Henri Bergson's élan vital [64], Alfred North Whitehead's process thinking [65], and Gilles Deleuze's lines of flight [66].

Part of the difficulty that many of us have today with adapting to the accelerating rates of change is that formal education trains ${ }^{5}$ children to think in fixed concepts, stunting their potential conceptual development and flexibility by fundamentalising concepts as dogmatic, unchanging facts. By contrast, postformal pedagogies that foreground conceptual imagination can be forces for conceptual vitality. This lays foundations for flexible, complex, innovative, process-oriented thinking, and a smooth transition to postformal reasoning at the appropriate developmental moment, in late adolescence or adulthood.

Several philosophers have emphasised the importance of imagination in education [67-70]. Yes formal education seems caught within the inertness of formal thinking, as neofundamentalist educational reform agendas write more stale ideas about the already said [67]. Deleuze challenges us "to bring something to life, to free life from where it is trapped, to trace lines of flight," (cited in [66, p. 287]. Such re-enlivened imaginative thinking is required to create new imaginaries of hope.

\section{Creating New Futures Narratives as Imaginaries of Hope}

'The lack of hope (of youth) for the future reflects the mistakes of the past, the problems of the present and the challenges of the future. But it also suggests a failure of vision, a failure to conceive a future that is appealing and plausible and able to serve as a focus and source of inspiration.' [71]

There is extensive psychological literature that has linked hopelessness with depression and suicide risk. Although there is a strong research and clinical base for targeting depression, there is a gap in the psychological literature when it comes to targeting hopelessness, specifically. Furthermore, research from the futures studies field indicates a rise in hopelessness, negativity and fear of the future among young people in the West [72]. A causal layered analysis [73] of youth suicidality demonstrates that below the surface of symptoms of cultural malaise, such as youth depression, anxiety and suicidality, and below the social, economic and psychological 'causes' we find that young people are disenchanted with the Western materialistic worldview [74]. Many young people are not inspired with

\footnotetext{
${ }^{4}$ Although not strongly emphasised in the postformal adult development literature, imagination is linked with postformal development by some researchers [20,35, 59].

${ }^{5}$ The term training in educational settings is a behaviourist metaphor and perhaps apt to describe much of modernist education; but my preference is for non-behaviourist terms.
} 
hope by the dominant worldview. Even deeper, underneath this worldview we can look for the deep story that young people are telling themselves about our world and their futures.

Futures researchers demonstrate that young people's images of the future have been colonised by a media-driven 'one and only probable future' which is negative and frightening [75]. The resultant 'culture of hopelessness' could partially explain the increases in both depression and suicide [76]. For many young people this malaise is a symptom of disenchantment with the world they are inheriting from their elders. Young people are idealistic when given a chance to express themselves. They want a clean, green world; they want a world with ethics and meaning - a world where everyone is treated fairly. They want work that is meaningful and where they are treated with respect and valued. Yet they expect the future to be full of their fears [77]. How can this be transformed?

Research from the youth futures field suggests that young people can be empowered by processes that allow them to create new stories of hope for their futures [76]. The possibility that the failure of the 'industrial myth' may underlie the future fears and disempowerment of youth, provides the motivation for the creation of new myths, new stories to inspire our youth and indeed, our culture to go forward. The task at this deep metaphoric level is to work from the imagination, especially involving young people to revision their world. What metaphors can be used for the human being-machine, ape or dolphin? [78]? Is knowledge a commodity or is it sacred? What metaphors can be used for school or university-Factory? Space ship? Garden? Community?

A number of positive media resources - particularly online resources - are being developed by researchers combining futures studies with media studies with the intention of nurturing imaginaries of hope especially for your people. ${ }^{6}$

\section{Playful Paradoxes of Planetary Pluralism}

Since evidence can be adduced and interpreted to corroborate a virtually limitless array of worldviews, the human challenge is to engage that world view or set of perspectives which brings forth the most valuable, life-enhancing consequences. [79, p. 406]

My own personal imaginary of hope for the planet and all its inhabitants is that we will develop the imagination to come to terms creatively with complexity and paradox in ways that will enable a richly diverse planetary pluralism. As a contrasting approach to the cultural homogenization implicit in globalization, we could use the alternative term coined in the 1950s by Teilhard de Chardin: planetization [80]. Teilhard de Chardin identified several postformal features in the planetization process - increasing complexity; the reflexion of the Noosphere upon itself; the closing of the spherical, thinking circuit; and the rebounding of evolution upon itself - a type of complex recursion [4, 81]. Such a notion of planetization involves not domination but awareness and respect for the richness of cultural diversity. He emphasized that this cannot by achieved merely by the pressure of external forces - such as totalizing governments - but needs to unfold from within human hearts "directly, centre to centre, through internal attraction ... through unanimity in a common spirit" (p. 112).

\footnotetext{
${ }^{6}$ The World Futures Studies Federation has begun to locate resources that provide a positive alternative to many of the dystopian images of the future provided by the mass media.

http://www.wfsf.org/index.php?option=com_content\&view=article\&id=277\&Itemid=144
} 
Perhaps we need to learn to consciously play with the paradoxes inherent in chaos and complexity, and place them at the service of our growing wisdom; to activate and embody our imaginations to re-vision our way out of the multiple challenges of postnormal times, by creating and telling each other new narratives that serve the common good, thus creating bounties of active hope for future generations. The planetary imaginary of hope envisaged by Teilhard de Chardin over sixty years ago was a mega-synthesis through which "the outcome of the world, the gates of the future ... will only open to an advance of all together, in a direction in which all together can join and find completion in a spiritual renovation of the earth" (pp. 243-245).

\section{References}

[1] Sardar, Z., Welcome to Postnormal Times. Futures: The journal of policy, planning and futures studies, 2010.

[2] Piaget, J., The Child's Construction of Reality. 1955, London: Routledge.

[3] Klement, K.C. Propositional Logic. Internet Encyclopedia of Philosophy 2005 [cited 2009 November 11]; Available from: http://www.iep.utm.edu/prop-log/.

[4] Gidley, J., The Evolution of Consciousness as a Planetary Imperative: An Integration of Integral Views. Integral Review: A Transdisciplinary and Transcultural Journal for New Thought, Research and Praxis, 2007. 5: p. 4-226.

[5] Gidley, J., An Other View of Integral Futures: De/reconstructing the IF Brand. Futures: The journal of policy, planning and futures studies, 2010. 42(2).

[6] Gidley, J., Evolving Education: A Postformal-integral-planetary Gaze at the Evolution of Consciousness and the Educational Imperatives, in Education. 2008, Southern Cross University: Lismore. p. 571.

[7] Gidley, J., Educating for evolving consciousness: Voicing the emergency for love, life and wisdom, in The international handbook of education for spirituality, care and wellbeing, M. de Souza, et al., Editors. 2009, Springer: New York. p. 533-561.

[8] Molz, M. and J. Gidley, A transversal dialogue on integral education and planetary consciousness: Markus Molz speaks with Jennifer Gidley. Integral Review: A Transdisciplinary and Transcultural Journal for New Thought, Research and Praxis, 2008. 6: p. 47-70.

[9] Steger, M.B., The rise of the global imaginary: Political ideologies from the French revolution to the global war on terror. 2008, Oxford: Oxford University Press.

[10] Gebser, J., The Ever-Present Origin. 1949/1985, Athens, Ohio: Ohio University Press.

[11] Morin, E. and A.B. Kern, Homeland Earth: A Manifesto for the New Millennium (Translated Sean Kelly, Roger Lapoint Advances in Systems Theory, Complexity and the Human Sciences, ed. A. Montuori. 1999, Cresskill, NJ: Hampton Press.

[12] Nandy, A., Recovery of Indigenous Knowledge and Dissenting Futures of Universities, in The University in Transformation: Global Perspectives on the Futures of the University, S. Inayatullah and J. Gidley, Editors. 2000, Bergin and Garvey: Westport, Connecticut. p. 270.

[13] Fromm, E., The Sane Society. 1955, New York, NY: Holt, Rinehart \& Winston.

[14] Laing, R.D., The divided self: An existential study in sanity and madness. 1960, Harmondsworth: Penguin.

[15] Szasz, T., Ideology and Insanity: Essays on the Psychiatric Dehumanisation of Man. 1974, London, UK: Penguin Books Ltd. 272.

[16] Marcuse, H., One-Dimensional Man: Studies in the Ideology of Advanced Industrial Society. 1964, Boston, MA: Beacon Press. 
[17] Foucault, M., Madness and Civilization: A History of Insanity in the Age of Reason. 1965, New York, NY: Random House.

[18] László, E., The Chaos Point: The World at the Crossroads. 2006, Charlottsville, VA: Hampton Roads Publishing Company, Inc.

[19] Klisanin, D., Designing media with intent: Evolutionary guidance media for the creation of planetary consciousness. 2003, Saybrook Graduate School and Research Center: California.

[20] Cook-Greuter, S.R., Mature Ego Development: A Gateway to Ego Transcendence. . Journal of Adult Development, 2000. 7(4): p. 227-240.

[21] Commons, M.L., et al., The existence of developmental stages as shown by the hierarchical complexity of tasks. Developmental Review, 1998. 8(3): p. 237-278.

[22] Wilber, K., Integral Psychology: Consciousness, Spirit, Psychology, Therapy. 2000, Boston: Shambhala. 302.

[23] Arlin, P.K., The Wise Teacher: A Developmental Model of Teaching Theory into Practice, 1999. 38(1): p. 12-17.

[24] Campbell, R.L. Jean Piaget's Genetic Epistemology: Appreciation and Critique. 2006 [cited; This is a revised version of two lectures presented at the Institute of Objectivist Studies Summer Seminar, Charlottesville, VA, July 7 and 8, 1997.]. Available from: http://hubcap.clemson.edu/ campber/piaget.html.

[25] Cartwright, K.B., Cognitive Developmental Theory and Spiritual Development. Journal of Adult Development 2001. 8(4): p. 213-220.

[26] Commons, M., et al., eds. Adult Development, Volume 2: Models and Methods in the Study of Adolescent and Adult Thought. 1990, Praeger: New York.

[27] Falcone, G.J., The relationship of postformal thought to conceptions of wisdom as mediated by age and education. 2000, Rutgers The State University of New Jersey New Brunswick and University of Medicine and Dentistry of New Jersey: New Jersey.

[28] Kegan, R., In Over Our Heads: the Mental Demands of Modern Life. 1994, Cambridge, Massachusetts: Harvard University Press.

[29] Kohlberg, L., Which Postformal Stages are Stages?, in Adult Development, Volume 2: Models and Methods in the Study of Adolescent and Adult Thought, M. Commons, et al., Editors. 1990, Praeger: Westport, CT.

[30] Kramer, D., A, Post-Formal Operations? A Need for Further Conceptualization. Human Development, 1983. 26: p. 91-105.

[31] Labouvie-Vief, G., Modes of knowledge and the organization of development, in Adult Development, Volume 2: Models and Methods in the Study of Adolescent and Adult Thought, M. Commons, et al., Editors. 1990, Praeger: Westport, CT. p. 43-62.

[32] Labouvie-Vief, G., Wisdom as Integrated Thought: Historical and Developmental Perspectives, in Wisdom: its Nature, Origins, and Development, R. Sternberg, J. and C.A. Berg, Editors. 1992, Cambridge University Press: Cambridge.

[33] Riegel, K., F, Dialectical Operations: The Final Period of Cognitive Development. Human Development, 1973. 16: p. 346-370.

[34] Sinnott, J.D., The Development of Logic in Adulthood: Postformal Thought and its Applications. Demick, Jack, ed. T.S.S.i.A.D.a. Aging. 1998, New York: Springer.

[35] Sinnott, J.D., The Dance of the Transforming Self: Both Feelings of Connection and Complex Thought are Needed for Learning. New Directions for Adult and Continuing Education, 2005. 108(Winter): p. 27-37.

[36] Yan, B. and P.K. Arlin, Nonabsolute/relativistic thinking: A common factor underlying models of postformal reasoning? Journal of Adult Development, 1995. 2(4): p. 223-240. 
[37] Commons, M.L. and F. Richards, A, Organizing Components into Combination: How Stage Transition Works. Journal of Adult Development, 2002. 9(3): p. 159-177.

[38] Griffin, J., et al., Four Brief Studies of Relations Between Postformal Thought and Non-Cognitive Factors: Personality, Concepts of God, Political Opinions, and Social Attitudes. Journal of Adult Development, 2009. 16(3): p. 173-182.

[39] Commons, M.L. and S.N. Ross, What Postformal Thought is and why is Matters. World Futures: The Journal of General Evolution, 2008. 64(5): p. 321-329.

[40] Comte, A., Positive Philosophy of Auguste Comte (H. Martineau, Trans.) (Original work published 1855) 1855/2003, Whitefish, MT: Kessinger Publishing.

[41] Spencer, H., Progess: Its Law and Causes. The Westminster Review, 1857. 67(April): p. 445-465.

[42] Barnard, A. and J. Spencer, eds. Encyclopaedia of Social and Cultural Anthropology. 1996/1998, Routledge: London.

[43] Kincheloe, J., S. Steinberg, and P.H. Hinchey, eds. The post-formal reader: Cognition and education Critical Education Practice, ed. S. Steinberg and J. Kincheloe. 1999, Falmer Press: New York.

[44] Morin, E., Organisation and Complexity. Annals New York Academy of Science, 1999. 879: p. 115-121.

[45] Morin, E. Restricted Complexity, General Complexity. in "Intelligence de la complexite : Epistemologie et pragmatique". 2005. Cerisy-La-Salle, France: Centre d'Etudes Transdisciplinaires. Sociologie, Anthropologie, Histoire, Ecole des Hautes Etudes en Sciences Sociales.

[46] Alhadeff-Jones, M., Three generations of complexity theories: Nuances and ambiguities. Educational Philosophy and Theory, 2008. 40(1): p. 66-82.

[47] Nicolescu, B., Manifesto of Transdisciplinarity (Translated by Karen-Claire Voss). Suny Series in Western Esoteric Traditions. 2002, New York: SUNY Press.

[48] Morin, E., Seven Complex Lessons in Education for the Future. 2001, Paris: UNESCO.

[49] Sternberg, R., J., Wisdom: Its nature, origins and development. 1990, New York: Cambridge Unversity Press.

[50] Sternberg, R., J., Why Schools Should Teach for Wisdom: The Balance Theory of Wisdom in Educational Settings. Educational psychologist, 2001. 36(4): p. 227-245.

[51] Koestler, A., The Act of Creation. 1964/1989, London: Arkana.

[52] Kaufman, J., C and J. Baer, Creativity and Reason in Cognitive Development. 2006, New York: Cambridge University Press.

[53] Kaufman, J., C and J. Baer, Creativity across domains: Faces of the muse. 2005, Mahwah, N.J.: Lawrence Erlbaum Associates.

[54] Gardner, H., An Education for the Future: The Foundation of Science and Values, in The Royal Symposium Convened by Her Majesty, Queen Beatrix. 2001: Amsterdam.

[55] Wilber, K. Introduction to Integral Theory and Practice: IOS Basic and the AQAL Map. 2004 [cited 2004; Available from: http://www.integralnaked.org.

[56] Klein, J.T., Prospects for Transdisciplinarity. Futures, 2004. 36(4): p. 515-526.

[57] Gidley, J., Globally scanning for mega-trends of the mind: Potential futures of futures thinking. Futures: The journal of policy, planning and futures studies, Forthcoming.

[58] Sloan, D., Insight-Imagination: the Emancipation of Thought and the Modern World. 1983, Westport, CT: Greenwood.

[59] Bassett, C. Wisdom in three acts: Using transformative learning to teach for wisdom [Electronic version]. in Sixth International Transformative Learning Conference. 2005. East Lansing, Michigan. 
[60] Boulding, E., Image and Action in Peace Building. Journal of Social Issues, 1988. 44(2): p. 17-37.

[61] Hutchinson, F., Educating beyond violent futures. Futures and Education Series, ed. R. Slaughter. 1996, London: Routledge. 304.

[62] Milojevic, I., Educational Futures: Dominant and Contesting Visions 2005, London: Routledge.

[63] Polak, F., The Image of the Future. 1973, San Francisco: Jossey-Bass.

[64] Fraser, M., S. Kember, and C. Lury, Inventive Life: Approaches to the New Vitalism. Theory, Culture \& Society, 2005. 22(1): p. 1-14.

[65] Gare, A., Speculative Metaphysics and the Future of Philosophy: The Contemporary Relevance of Whitehead's Defence of Speculative Metaphysics. Australasian Journal of Philosophy, 1999. 77(2): p. 127-145.

[66] St. Pierre, E.A., Deleuzian concepts for education: The subject undone. Educational Philosophy and Theory 2004. 36(3): p. 283-296.

[67] Lyotard, J.-F., The Postmodern Condition: A Report on Knowledge. 2004, Manchester: Manchester University Press.

[68] Nuyen, A.T., Jean-Francois Lyotard: Education for Imaginative Knowledge, in Naming the Multiple: Poststructuralism and Education, M. Peters, Editor. 1998, Bergin \& Garvey: Westport, CT.

[69] Warnock, M., Imagination. 1976, Berkeley, CA: University of California Press.

[70] Whitehead, A.N., Discussion upon Fundamental Principles of Education. Process Studies, 1919. 14(1): p. 41-43.

[71] Eckersley, R., Having our Say about the Future: Young People's Dreams and Expectations for Australia in 2010 and the Role of Science and Technology. 1996, Australian Science and Technology Council.

[72] Gidley, J., The metaphors of globalisation: A multi-layered analysis of global youth culture, in The causal layered analysis (CLA) reader: Theory and case studies of an integrative and transformative methodology, S. Inayatullah, Editor. 2004, Tamkang University: Taipei.

[73] Inayatullah, S., Causal Layered Analysis: Poststructuralism as method. Futures, 1998. 30(8): p. 815-829.

[74] Gidley, J., Giving Hope back to our Young People: Creating a New Spiritual Mythology for Western Culture. Journal of Futures Studies: Epistemology, Methods, Applied and Alternative Futures, 2005. 9(3): p. 17-30.

[75] Hutchinson, F., Cultural Mapping and Our Children's Future: Decolonising Ways of Learning and Research, in Youth Futures: Comparative Research and Transformative Visions, J. Gidley and S. Inayatullah, Editors. 2002, Praeger: Westport, CT. p. 53-64.

[76] Gidley, J., An Intervention Targeting Hopelessness in Adolescents by Promoting Positive Future Images. Australian Journal of Guidance and Counselling, 2001. 11(1): p. 51-64.

[77] Gidley, J. and S. Inayatullah, Youth Futures: Comparative Research and Transformative Visions. 2002, Westport, CT: Praeger.

[78] Hampson, G.P., Evolutionary Metaphors of Human Futures: Machine, Ape or Dolphin? . Journal of Futures Studies, 2005. 9(4): p. 29-44.

[79] Tarnas, R., The Passions of the Western Mind. 1991, New York: Random House.

[80] Teilhard de Chardin, P., The Phenomenon of Man. 1959/2002, New York: Perennial.

[81] Morin, E., RE: from Prefix to Paradigm. World Futures: the Journal of General Evolution, 2005. 61: p. 254-267. 